\title{
Familial juvenile polyposis syndrome with a de novo germline missense variant in BMPR1A gene: a case report
}

\author{
Qing Liu, Mengling Liu, Tianshu Liu and Yiyi Yu* (B)
}

\begin{abstract}
Background: Juvenile polyposis syndrome (JPS) is a rare autosomal dominant hereditary disorder characterized by the development of multiple distinct juvenile polyps in the gastrointestinal tract with an increased risk of colorectal cancer. Germline mutations in two genes, SMAD4 and BMPR1A, have been identified to cause JPS.

Case presentation: Here, we report a germline heterozygous missense variant (c.299G > A) in exon 3 BMPR1A gene in a family with juvenile polyposis. This variant was absent from the population database, and concluded as de novo compared with the parental sequencing. Further sequencing of the proband's children confirmed the segregation of this variant with the disease, while the variant was also predicted to have damaging effect based on online prediction tools. Therefore, this variant was classified as likely pathogenic according to the American College of Medical Genetics and Genomics (ACMG) guidelines.

Conclusions: Germline genetic testing revealed a de novo germline missense variant in BMPR1A gene in a family with juvenile polyposis. Identification of the pathogenic variant facilitates the cancer risk management of at-risk family members, and endoscopic surveillance is recommended for mutation carriers.
\end{abstract}

Keywords: Juvenile polyposis syndrome, BMPRTA gene, De novo germline variant, Missense variant

\section{Background}

Juvenile polyposis syndrome (JPS) is a rare autosomal dominant hereditary disorder characterized by the development of multiple distinct juvenile polyps in the gastrointestinal tract with an increased risk of colorectal cancer [1,2]. Clinically, JPS is defined by the presence of more than five juvenile polyps in the colorectum, and/or juvenile polyps outside the colon, and/or any number of juvenile polyps with a family history of juvenile polyposis [3]. Histologically, these polyps are characterized by an abundance of edematous lamina propria with mucin-filled cystic dilations and inflammatory infiltrate [4]. Germline mutations in

\footnotetext{
* Correspondence: flame520@hotmail.com

Department of Medical Oncology, Zhongshan Hospital, Fudan University, 180 Fenglin Road, Shanghai 200032, China
}

two genes, SMAD4 and BMPR1A, have been identified to cause JPS [5]. Both genes are members of the transforming growth factor beta (TGF- $\beta$ ) superfamily, and pathogenic mutations in the coding region of each gene have been found in $~ 20 \%$ of JPS patients, respectively [6]. Here we report a de novo germline missense variant in BMPR1A gene in a family with juvenile polyposis.

\section{Case presentation}

The 35-year-old male proband was first presented with rectal bleeding for 2 months in September 2015 (Fig. 1). Colonoscopy was then conducted and revealed dozens of pedunculated polyps of different sizes (range of $5-30 \mathrm{~mm}$ ), distributed along the entire length of the colon. The histological analysis showed juvenile and adenomatous polyp with low-grade

(c) The Author(s). 2020 Open Access This article is licensed under a Creative Commons Attribution 4.0 International License, which permits use, sharing, adaptation, distribution and reproduction in any medium or format, as long as you give appropriate credit to the original author(s) and the source, provide a link to the Creative Commons licence, and indicate if changes were made. The images or other third party material in this article are included in the article's Creative Commons licence, unless indicated otherwise in a credit line to the material. If material is not included in the article's Creative Commons licence and your intended use is not permitted by statutory regulation or exceeds the permitted use, you will need to obtain permission directly from the copyright holder. To view a copy of this licence, visit http://creativecommons.org/licenses/by/4.0/ The Creative Commons Public Domain Dedication waiver (http://creativecommons.org/publicdomain/zero/1.0/) applies to the data made available in this article, unless otherwise stated in a credit line to the data. 


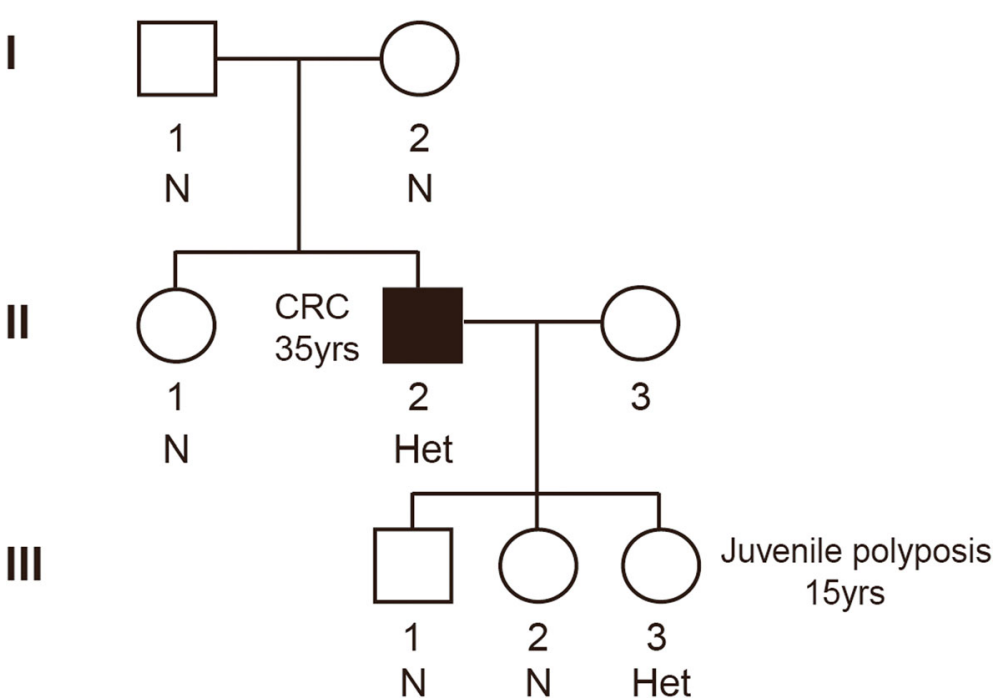

Fig. 1 The pedigree of the family investigated in this study, with the proband indicated by the black shading. Age of onset is noted beside the family member. The status of BMPRIA variant is listed beneath each family member. CRC, colorectal cancer. N, none. Het, heterozygous

dysplasia. The proband received a right hemicolectomy in January 2016 for a T3N0M0 moderately differentiated adenomatous carcinoma of the transverse colon but developed liver and lung metastasis in 2018.

The patient's parents (I-1, I-2) and his sister (II-1) were healthy without any symptoms when the proband was diagnosed with colorectal cancer (CRC). His three children (III-1, III-2 and III-3) had colonoscopy in 2018 (at the age of 12,18 and 15 respectively), one of which (III-3) was found to have 3 polyps. Endoscopic mucosal resection was then performed to fully remove these polyps and histology was consistent with juvenile polyp.

\section{Germline genetic testing}

Given the clinicopathological findings and the family history, the diagnosis was familial juvenile polyposis. Subsequently, germline genetic testing via a multigene panel (66 genes), which included genes associated with hereditary tumors such as APC, BMPR1A, BRCA1, BRCA2, MMR genes, MUTYH, PTEN, SMAD4, STK11, $P O L D 1$ and POLE, was performed on the proband and his family members. Finally, an unreported heterozygous c.299G > A (p.Cys100Tyr) missense mutation in exon 3 of the BMPR1A gene (NM_004329) was identified. The variant was further confirmed by Sanger sequencing (Fig. 2), and concluded as de novo compared with the parental sequencing. The c.299G > A (p.Cys100Tyr) variant was absent from the dbSNP, the 1000G, ESP and ExAC databases. Furthermore, this variant was predicted as damaging according to online prediction tools including SIFT, Polyphen2 and Mutation Taster. Moreover, the proband's two children (III-1, III-2) who had negative findings from colonoscopy did not carry this variant. Only the individual III-3 who presented with polyps had this variant, indicating the co-segregation of the variant in this family (Fig. 1).

According to the latest American College of Medical Genetics and Genomics (ACMG) guidelines for the interpretation of sequence results, this variant in BMPR1A gene fulfills PS2, PM2, PP1 and PP3 and is therefore regarded as likely pathogenic [7].

\section{Discussion and conclusions}

BMPR1A is a serine-threonine kinase receptor, with a cysteine-rich extracellular region, an intracellular glycine-serine-rich domain, and an intracellular kinase domain [8]. It is involved in the TGF- $\beta$ signaling pathway which is an important regulator of various cellular processes, including proliferation, differentiation, migration and death [9]. Several different types of mutations of the BMPR1A gene have been identified in JPS patients, including large deletions, missense and nonsense substitutions, and small indels that result in frameshift mutations $[1,6,10]$. However, the functional consequences of missense variants are not always as obvious. The substitution of one amino acid for another may or may not have deleterious effect on the structural properties with the corresponding proteins. Hence, such variants are regarded as "variants of uncertain significance" (VUS). 


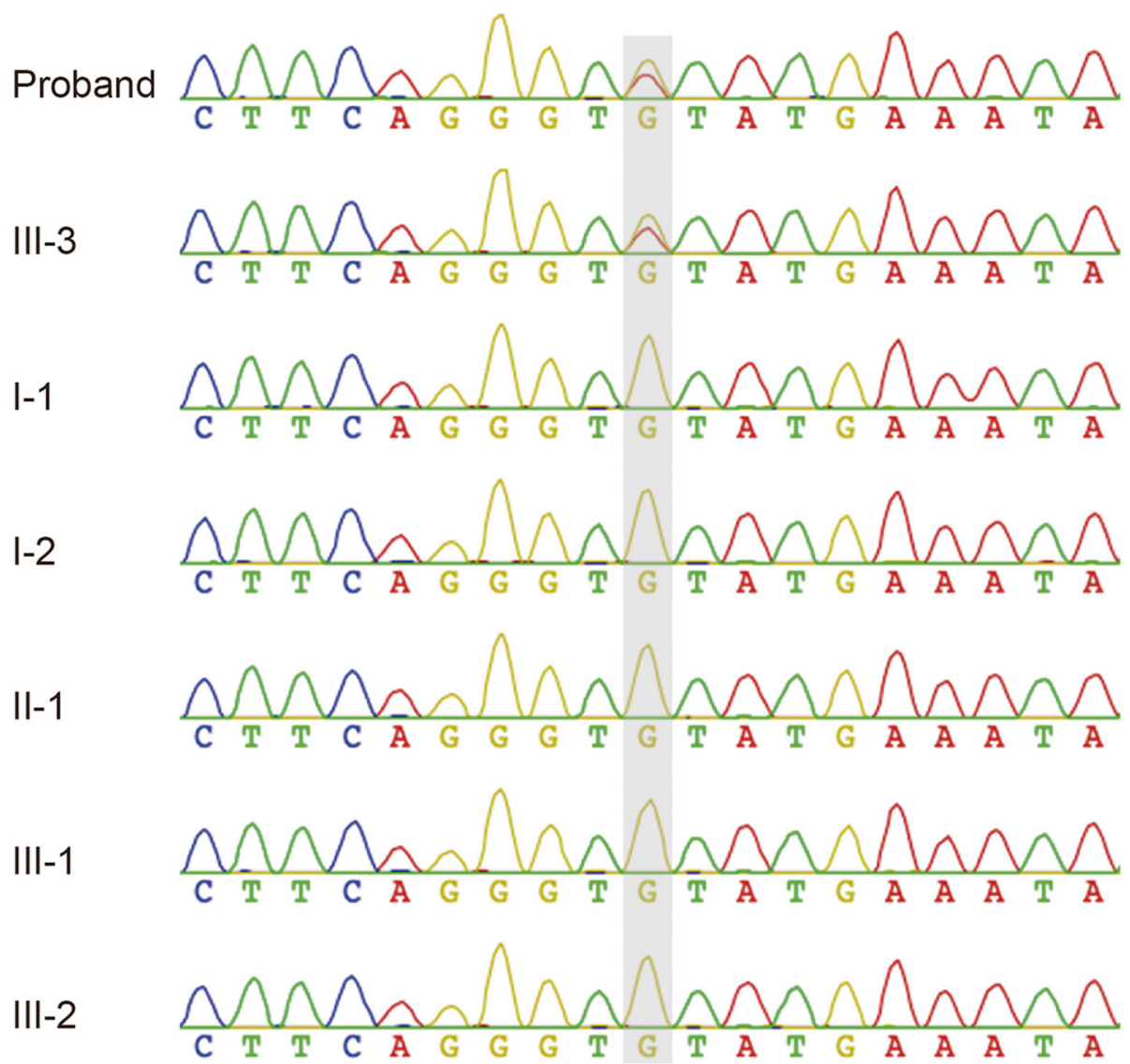

Fig. 2 Missense variant (c.299G > A) in the BMPR1A gene confirmed by sanger sequencing of the family

Several studies have characterized the feature of missense variants in BMPR1A gene functionally in vitro. Using confocal microscopy and luciferase assays, Howe et al. [11] found that missense variants in BMPR1A could have damaging impact on the localization of the protein to cell membrane instead of reducing protein levels. Kotzsch et al. [12] showed that extracellular domain variants could inactivate BMP-2 signaling by depriving their folding ability compared with wild-type protein. Yet the pathogenicity of these variants in vivo is still inconclusive. A further study is needed, i.e. functional study to prove that this new de novo missense variant in exon 3 $B M P R 1 A$ gene in this study is pathogenic variant. Missense variants of BMPR1A gene identified in JPS patients reported in PubMed from 2000 to 2019, including the present case, are summarized in Table 1, with the pathogenicity evaluated according to ACMG guidelines [6,10, 13-25]. Most of the previous reported missense variants are classified as VUS except for c.1328G > A, another de novo missense variant listed as likely pathogenic [24].
Here, we identified a germline missense variant in BMPR1A gene in a family with juvenile polyposis. This variant is classified as likely pathogenic variant based on multiple lines of evidence. First, absence of the c.299G > A (p.Cys100Tyr) variant in both parents validated its de novo status. Further sequencing of the proband's children confirmed the segregation of this variant with the disease. Second, no missense variant has been reported in the population databases at this position. Third, the p.Cys100Tyr is located within the cysteine-rich domain, a highly-conserved ectodomain of the TGF- $\beta$ receptor family, which is very likely to result in conformational alterations (suppl Fig. 1) [26]. In silico analysis using multiple computational tools also shows damaging effect of this variant.

For patients with JPS, endoscopic surveillance should be performed yearly until the patient is deemed to be polyp free [27]. Therefore, genetic testing for at-risk family members is an important procedure in the management. In this case, the proband's daughter (III-3) who carry the missense variant should receive high-risk 
Table 1 Missense Variants of BMPR1A gene identified in JPS patients

\begin{tabular}{|c|c|c|c|c|c|}
\hline Nucleotide variant & dbSNP number & Protein change & ACMG guideline [7] & Pathogenicity & Ref \\
\hline C. $1 A>C$ & rs786203157 & p.Met1Leu & PM2 PP3 & VUS & [13] \\
\hline$c .4 C>A$ & rs11528010 & p.Pro2Thr & $\mathrm{BA} 1$ & benign & [10] \\
\hline C. $170 C>G$ & rs1057517610 & p.Pro57Arg & PM2 PP3 & VUS & {$[6,13,14]$} \\
\hline c. $184 T>G$ & / & p.Tyr62Asp & PM2 PP3 & VUS & {$[6,14,15]$} \\
\hline$c .233 C>T$ & rs1064793490 & p.Thr78lle & PM2 PP1 PP3 & VUS & {$[6,13,16]$} \\
\hline$c .238 G>A$ & / & p.Gly80Arg & PM2 & VUS & {$[17]$} \\
\hline c. $245 G>A$ & / & p.Cys82Tyr & PM2 PP3 & VUS & {$[6,13,15]$} \\
\hline c. $299 G>A$ & / & p.Cys100Tyr & PS2 PM2 PP1 PP3 & likely pathogenic & this study \\
\hline c. $355 C>T$ & rs587782494 & p.Arg119Cys & PM2 & VUS & {$[17]$} \\
\hline c.359G >C & / & p.Arg120Pro & PM2 PP3 & VUS & [18] \\
\hline c. $370 \mathrm{~T}>\mathrm{C}$ & rs199476087 & p.Cys124Arg & PM2 & VUS & [19] \\
\hline c. $373 \mathrm{~T}>\mathrm{G}$ & rs1131691180 & p.Cys125Gly & PM2 PP3 & VUS & [18] \\
\hline c. $385 \mathrm{~T}>\mathrm{A}$ & / & p.Leu129\|le & PM2 BP4 & VUS & [18] \\
\hline c.388 T > C & rs1131691168 & p.Cys130Arg & PM2 PP3 & VUS & {$[17,20]$} \\
\hline c. $524 \mathrm{G}>\mathrm{A}$ & rs370091063 & p.Cys175Tyr & PP3 BP6 & VUS & [21] \\
\hline c.761G > A & rs766908700 & p.Arg254His & PP3 BS2 & VUS & [13] \\
\hline c. $872 \mathrm{~T}>\mathrm{C}$ & / & p.Phe291Ser & PM2 PP3 & VUS & [18] \\
\hline $\mathrm{c} .955 \mathrm{~T}>\mathrm{C}$ & / & p.Leu332Pro & PM2 PP3 & VUS & [22] \\
\hline c. $1013 C>A$ & rs199476086 & p.Ala338Asp & PM2 PP3 & VUS & {$[6,15,19]$} \\
\hline c. $1058 \mathrm{~A}>\mathrm{G}$ & rs1405441693 & p.Gln353Arg & PM2 PP3 & VUS & {$[22]$} \\
\hline c. $1127 G>A$ & rs199476088 & p.Cys376Tyr & PM2 PP3 & VUS & [19] \\
\hline c. $1229 \mathrm{C}>\mathrm{T}$ & / & p.Pro410Leu & PM2 & VUS & [17] \\
\hline c. $1231 \mathrm{G}>\mathrm{A}$ & rs786202611 & p.Glu411Lys & PM2 PP3 & VUS & [23] \\
\hline c. $1242 \mathrm{G}>\mathrm{A}$ & rs140592056 & p.Glu415Lys & PP3 & VUS & [18] \\
\hline c. $1327 \mathrm{C}>\mathrm{T}$ & rs35619497 & p.Arg443Lys & PP3 PP5 BP6 & VUS & {$[6,13,15,18]$} \\
\hline c. $1328 \mathrm{G}>\mathrm{A}$ & rs876659155 & p.Arg443His & PS2 PM2 PP3 & likely pathogenic & {$[24]$} \\
\hline c.1409T >C & rs199476089 & p.Met470Thr & PM2 PP3 & VUS & [25] \\
\hline c. $1433 \mathrm{G}>\mathrm{A}$ & rs113849804 & p.Arg478His & PP3 & VUS & {$[22]$} \\
\hline c. $1438 \mathrm{C}>\mathrm{T}$ & rs876658515 & p.Arg480Trp & PM2 PM5 PP3 & VUS & {$[10]$} \\
\hline
\end{tabular}

surveillance to prevent the development of cancer, while his other two children (noncarriers) may no longer require close endoscopic screening.

In summary, we report a de novo germline heterozygous missense variant in exon 3 BMPR1A gene in a family with juvenile polyposis. Identification of the pathogenic variant facilitates the cancer risk management of at-risk family members, and endoscopic surveillance is recommended for mutation carriers.

\section{Supplementary information}

Supplementary information accompanies this paper at https://doi.org/10. 1186/s12881-020-01135-6.

Additional file 1 : Suppl Fig. 1 The upper rectangle represents the different domains of the BMPRTA gene. The lower panel shows analysis of evolutionary conserved amino acids in human BMPR1A protein predicted by ConSurf.

Abbreviations

JPS: Juvenile polyposis syndrome; ACMG: American College of Medical Genetics and Genomics;i TGF- $\beta$ : Transforming growth factor beta; CRC: Colorectal cancer; VUS: Variants of uncertain significance

Acknowledgements

The authors thank the patient and his family for their invaluable contribution to this study.

\section{Authors' contributions}

QL and MLL did the data analysis and interpretation. QL was the major contributor in writing the manuscript. Both TSL and YYY gave constructive suggestions for the study, and YYY was critical for the manuscript revision. All authors have read and approved the manuscript. 


\section{Funding}

This study was supported by the National Natural Science Foundation of China (No. 81802356). The funders had no role in study design, data collection and analysis, decision to publish, or preparation of the manuscript.

\section{Availability of data and materials}

The raw datasets generated and/or analyzed during the current study are not publicly available in order to protect participant confidentiality, but are available from the corresponding author on reasonable request.

\section{Ethics approval and consent to participate}

All procedures followed were in accordance with the ethical standards of the responsible committee on human experimentation (institutional and national) and with the Helsinki Declaration of 1975, as revised in 2008(5). This study has been approved by Ethics Committee of Zhong Shan Hospital affiliated to Fudan University (Approval No. B2020-073). A written form of informed consent was obtained from all the individuals to be included in the study and a written form of informed consent to participate was obtained from the parents of the participants (under the age of 16).

\section{Consent for publication}

Written informed consent for publication of clinical details and clinical images was obtained from the all individuals to be included in the study. Written informed consent for publication of clinical details and clinical images was obtained from the parents the participant under the age of 18

\section{Competing interests}

The authors declare that there are no conflicts of interest.

Received: 27 June 2020 Accepted: 28 September 2020

Published online: 08 October 2020

\section{References}

1. Woodford-Richens K, Bevan S, Churchman M, et al. Analysis of genetic and phenotypic heterogeneity in juvenile polyposis. Gut. 2000;46(5):656-60.

2. Schreibman IR, Baker M, Amos C, McGarrity TJ. The hamartomatous polyposis syndromes: a clinical and molecular review. Am J Gastroenterol. 2005;100(2):476-90.

3. Jass JR, Williams CB, Bussey HJ, Morson BC. Juvenile polyposis: a precancerous condition. Histopathology. 1988;13(6):619-30

4. Menko FH, Kneepkens CM, de Leeuw N, et al. Variable phenotypes associated with 10q23 microdeletions involving the PTEN and BMPR1A genes. Clin Genet. 2008;74(2):145-54.

5. Howe JR, Bair JL, Sayed MG, et al. Germline mutations of the gene encoding bone morphogenetic protein receptor $1 \mathrm{~A}$ in juvenile polyposis. Nat Genet. 2001:28(2):184-7.

6. Howe JR, Sayed MG, Ahmed AF, et al. The prevalence of MADH4 and BMPR1A mutations in juvenile polyposis and absence of BMPR2, BMPR1B, and ACVR1 mutations. J Med Genet. 2004;41(7):484-91.

7. Richards S, Aziz N, Bale S, et al. Standards and guidelines for the interpretation of sequence variants: a joint consensus recommendation of the American College of Medical Genetics and Genomics and the Association for Molecular Pathology. Genet Med. 2015;17(5):405-24.

8. Heldin CH, Miyazono K, ten Dijke P. TGF-beta signalling from cell membrane to nucleus through SMAD proteins. Nature. 1997:390(6659):465-71.

9. Waite KA, Eng C. From developmental disorder to heritable cancer: it's all in the BMP/TGF-beta family. Nat Rev Genet. 2003;4(10):763-73.

10. van Hattem WA, Brosens LA, de Leng WW, et al. Large genomic deletions of SMAD4, BMPR1A and PTEN in juvenile polyposis. Gut. 2008:57(5):623-7.

11. Howe JR, Dahdaleh FS, Carr JC, Wang D, Sherman SK, Howe JR. BMPR1A mutations in juvenile polyposis affect cellular localization. J Surg Res. 2013; 184(2):739-45.

12. Kotzsch A, Nickel J, Seher A, et al. Structure analysis of bone morphogenetic protein-2 type I receptor complexes reveals a mechanism of receptor inactivation in juvenile polyposis syndrome. J Biol Chem. 2008;283(9):5876-87.

13. Calva-Cerqueira D, Chinnathambi S, Pechman B, Bair J, Larsen-Haidle J, Howe JR. The rate of germline mutations and large deletions of SMAD4 and BMPR1A in juvenile polyposis. Clin Genet. 2009;75(1):79-85.

14. Lynch HT, Tinley ST, Shaw TG, Lynch JF, Howe JR, Attard TM. Challenging colonic polyposis pedigrees: differential diagnosis, surveillance, and management concerns. Cancer Genet Cytogenet. 2004;148(2):104-17.
15. Sayed MG, Ahmed AF, Ringold JR, et al. Germline SMAD4 or BMPR1A mutations and phenotype of juvenile polyposis. Ann Surg Oncol. 2002;9(9):901-6.

16. Kurland JE, Beck SE, Solomon CJ, Brann OS, Carethers JM, Huang SC Cyclooxygenase-2 expression in polyps from a patient with juvenile polyposis syndrome with mutant BMPR1A. J Pediatr Gastroenterol Nutr. 2007:44(3):318-25.

17. Aretz $S$, Stienen D, Uhlhaas $S$, et al. High proportion of large genomic deletions and a genotype phenotype update in 80 unrelated families with juvenile polyposis syndrome. J Med Genet. 2007;44(11):702-9.

18. Ngeow J, Heald B, Rybicki LA, et al. Prevalence of germline PTEN, BMPR1A, SMAD4, STK11, and ENG mutations in patients with moderate-load colorectal polyps. Gastroenterology. 2013;144(7):1402-9.

19. Zhou XP, Woodford-Richens $K$, Lehtonen $R$, et al. Germline mutations in BMPR1A/ALK3 cause a subset of cases of juvenile polyposis syndrome and of Cowden and Bannayan-Riley-Ruvalcaba syndromes. Am J Hum Genet. 2001;69(4):704-11.

20. Friedl W, Uhlhaas S, Schulmann K, et al. Juvenile polyposis: massive gastric polyposis is more common in MADH4 mutation carriers than in BMPR1A mutation carriers. Hum Genet. 2002;111(1):108-11.

21. Jelsig AM, Brusgaard K, Hansen TP, et al. Germline variants in Hamartomatous polyposis syndrome-associated genes from patients with one or few hamartomatous polyps. Scand J Gastroenterol. 2016;51(9):1118-25.

22. Pearlman R, Frankel WL, Swanson B, et al. Prevalence and Spectrum of Germline Cancer susceptibility gene mutations among patients with earlyonset colorectal Cancer. JAMA Oncol. 2017;3(4):464-71.

23. Pyatt RE, Pilarski R, Prior TW. Mutation screening in juvenile polyposis syndrome. J Mol Diagn. 2006;8(1):84-8.

24. Chubb D, Broderick P, Frampton M, et al. Genetic diagnosis of high-penetrance susceptibility for colorectal cancer (CRC) is achievable for a high proportion of familial CRC by exome sequencing. J Clin Oncol. 2015;33(5):426-32.

25. Kim IJ, Park JH, Kang HC, et al. Identification of a novel BMPR1A germline mutation in a Korean juvenile polyposis patient without SMAD4 mutation. Clin Genet. 2003:63(2):126-30.

26. Kirsch T, Sebald W, Dreyer MK. Crystal structure of the BMP-2-BRIA ectodomain complex. Nat Struct Biol. 2000;7(6):492-6.

27. Howe JR, Ringold JC, Hughes JH, Summers RW. Direct genetic testing for Smad4 mutations in patients at risk for juvenile polyposis. Surgery. 1999; 126(2):162-70

\section{Publisher's Note}

Springer Nature remains neutral with regard to jurisdictional claims in published maps and institutional affiliations.

Ready to submit your research? Choose BMC and benefit from:

- fast, convenient online submission

- thorough peer review by experienced researchers in your field

- rapid publication on acceptance

- support for research data, including large and complex data types

- gold Open Access which fosters wider collaboration and increased citations

- maximum visibility for your research: over $100 \mathrm{M}$ website views per year

At BMC, research is always in progress.

Learn more biomedcentral.com/submissions 